\title{
She - Aplicativo Móvel Para Mulheres Obterem Informações E Ajuda sobre Abusos
}

She - Mobile App for women find information and help about Sexual Harassment.

Andrade, Amanda Carolina Moreira de; Estudante; FAAL - Faculdade de Administração e Arte de Limeira.

amandacarolina.ma@gmail.com

\section{Resumo}

No Brasil, uma mulher é estuprada a cada 11 minutos (IPEA - INSTITUTO DE PESQUISA ECONÔMICA APLICADA, 2014), número que representa apenas os casos denunciados, somando $10 \%$ dos casos totais estimados. Em frente a essa estatística, surge a necessidade de uma maneira mais prática e rápida para essas vítimas buscarem ajuda, e se informarem em casos de necessidade. Como maneira de facilitar o encontro de informações e recursos sobre o assunto, foi definido a criação de um aplicativo móvel. A viabilidade e usabilidade do projeto foi definida baseando-se nos dados de que pela primeira vez, em 2014 o número de usuários acessando a internet no Brasil por celulares superou o de computadores (IBGE - INSTITUTO BRASILEIRO DE GEOGRAFIA E ESTATÍSTICA, 2014), e de que o número de mulheres, entre 10 à 39 anos, usuárias de telefonia móvel superou o número de usuários homens (IBGE - INSTITUTO BRASILEIRO DE GEOGRAFIA E ESTATÍSTICA, 2011). Baseado nos conceitos apresentados por Munari (MUNARI, 1998), este trabalho foi realizado para entender como o problema seria resolvido da melhor maneira, e seguindo a metodologia de Garret (GARRET, 2011), foi possível entender como o design e usabilidade podem facilitar a pesquisa de informações dentro de um aplicativo móvel, resultando então, a partir do uso de técnicas e pesquisas sobre Experiência do Usuário e Interface, um aplicativo voltado para o público-alvo.

Palavras Chave: Abuso Feminino; Aplicativo; Experiência do Usuário.

\section{Abstract}

In Brazil, a woman is raped every 11 minutes (IPEA - INSTITUTO DE PESQUISA ECONÔMICA APLICADA, 2014), which represents only the reported cases, accounting for $10 \%$ of the estimated total cases. Faced with this statistic, the need arises for a more practical and quick way for these victims to seek help and inform themselves in cases of need. As a way to facilitate the collection of information and resources on the subject, the creation of a mobile application was defined. The feasibility and usability of the project were defined based on data that for the first time, in 2014, the number of users accessing the Internet in Brazil by mobile phones exceeded the number of computers (IBGE - INSTITUTO BRASILEIRO DE GEOGRAFIA E ESTATISTICA, 2014) and that the number of women between 10 and 39 years of age, mobile users, exceeded the number of male users (IBGE - INSTITUTO BRASILEIRO DE GEOGRAFIA E ESTATÍSTICA, 2011). Based on the concepts presented by Munari (MUNARI, 1998), this work was carried out to understand how the problem would be solved in the best way, and following the methodology of Garret (GARRET, 2011), it was possible to understand how the design and usability can facilitate the search of information inside 


\section{Artigo Completo}

a mobile application, resulting in the use of research techniques of user experience and interface, an application aimed at the target audience.

Keywords: Female abuse; App; User Xperience. 


\section{Introdução}

Segundo 0 10ำ Anuário Brasileiro de Segurança Pública (FORUM BRASILEIRO DE SEGURANÇA PÚBLICA, 2016, p. 35), no Brasil, uma mulher a cada 11 minutos é violentada, estatística que assusta a primeiro momento e que revela a importância em se falar do assunto e fazer algo a respeito. Uma análise minuciosa mostra que $56 \%$ dos agressores são homens da família ou amigos e conhecidos (IPEA - INSTITUTO DE PESQUISA ECONÔMICA APLICADA, 2014, p. 10).

No Brasil durante o ano de 2015 foram registrados 45.460 casos de estupro segundo o 10은 Anuário Brasileiro de Segurança Pública (FORUM BRASILEIRO DE SEGURANÇA PÚBLICA, 2016, p. $35)$, número que representa apenas $10 \%$ das tentativas ou casos consumados de, já que $90 \%$ das vítimas não denunciam, indicando que haja um número aproximado de 527 mil casos anualmente.

Em frente a essas estatísticas alarmantes, o presente trabalho busca entender qual a melhor forma de ajudar, informar e orientar as vítimas quando casos como estes ocorrem. A proposta é, seguindo os princípios do Design, desenvolver um aplicativo móvel, partindo primeiramente da criação de logotipo e projetar com o auxílio de princípios da Experiência do Usuário e do Design de Interface, a aplicação que funcione de uma maneira fácil e rápida para que mulheres possam buscar informações com sigilo em situações de risco e pós-traumáticas.

O desenvolvimento do projeto se torna viável e justificável a partir do momento que se analisa as estatísticas de uso de aparelhos móveis no Brasil, que segundo site da Exame, no final de 2014, o país era o 60 no mercado mundial de smartphones (DINO, 2016). Adicionado a esse fato, segundo o IBGE, o número de usuárias mulheres de telefonia móvel entre 10 e 39 anos supera o número de usuários homens (IBGE - INSTITUTO BRASILEIRO DE GEOGRAFIA E ESTATÍ́STICA, 2011, p. 12).

\section{Objetivos}

O objetivo deste projeto foi entender a situação do público-alvo, qual a melhor maneira de resolver o problema, analisar a viabilidade de criação de um produto e por fim, desenvolver um aplicativo móvel, de maneira a facilitar mulheres a encontrar ajuda sobre abusos sexuais.

\section{Método para levantamento e análise de dados}

Para que o trabalho fosse fundamentado e validado, foram usados dois métodos de pesquisa, o primeiro de Bruno Munari, descrito no livro das Coisas nascem Coisas, juntamente com o método de Jesse Garrett no livro The Elements of User Experience.

A partir do processo de pesquisa de Bruno Munari, é possível, seguindo os passos descritos, encontrar a melhor solução para o problema apresentado. O autor, em seu livro Das Coisas nascem Coisas, divide o processo em passos (MUNARI, 1998, p. 29-55), sendo eles Problema (P), Definição do Problema (DP), Componentes do Problema (CP), Coleta de Dados (CD), Análise de Dados (AD), Criatividade (C), Materiais e Tecnologias (MT), Experimentação (E), Modelo (M), Verificação (V), Desenhos Construtivos (DF) e Solução (S). No desenvolvimento dessa pesquisa, a partir da etapa de Criatividade (C) o método utilizado foi o de Garret, que baseia-se em 
5 planos para projetar produtos de acordo com a melhor experiência para o usuário final, sendo eles, Estratégia, Escopo, Estrutura, Esqueleto e Superfície (GARRET, 2011).

Cada etapa baseou-se no usuário final para garantir a viabilidade do desenvolvimento do projeto. A partir de pesquisa com o público-alvo, pode-se definir estratégias, propósitos, funcionalidades e melhorias, para que fosse possível resultar na solução mais viável de atender às necessidades.

\subsection{Problema}

Existe no Brasil um grande número de mulheres que sofrem abusos sexuais durante sua vida, já que uma mulher é estuprada a cada 11 minutos (IPEA - INSTITUTO DE PESQUISA ECONÔMICA APLICADA, 2014). A falta de informações e meios de acesso a elas, é um dos fatores que fazem com que as vítimas não busquem ajuda ou se informem sobre o assunto.

A partir desse cenário, torna-se necessário a criação de uma maneira de facilitar com que as vítimas encontrem as informações que precisam para então tomar a decisão de buscar algum profissional que a auxilie daquele ponto em diante.

\subsection{Definição do Problema}

Adicionado as estatísticas apresentadas pelo 10 Anuário Brasileiro de Segurança Pública, de que 45.460 casos de estupros foram registrados em 2015 (FORUM BRASILEIRO DE SEGURANÇA PÚBLICA, 2016, p. 35), uma pesquisa feita com 48 mulheres entre os dias 13 de junho de 2018 e 18 de junho de 2018, em sua maioria de 18 a 25 anos, foi constatado que 60,4\% das entrevistadas já tinha sofrido algum tipo de Abuso Sexual, definido na legislação como:

\footnotetext{
III - a violência sexual, entendida como qualquer conduta que a constranja a presenciar, a manter ou a participar de relação sexual não desejada, mediante intimidação, ameaça, coação ou uso da força; que a induza a comercializar ou a utilizar, de qualquer modo, a sua sexualidade, que a impeça de usar qualquer método contraceptivo ou que a force ao matrimônio, à gravidez, ao aborto ou à prostituição, mediante coação, chantagem, suborno ou manipulação; ou que limite ou anule o exercício de seus direitos sexuais e reprodutivos; (Lei № 11.340, de 7 de agosto de 2006).
}

Além desse número, 22,9\% das entrevistadas disseram não saber definir se o que tinham passado se caracterizava como abuso. Na mesma pesquisa, $87,5 \%$ das entrevistadas disseram conhecer alguém que já passou por alguma situação de abuso.

A falta de opções para busca de informações e auxílio a respeito de abuso sexual torna-se um problema que deve ser resolvido, já que $75 \%$ das mulheres que sofreram abuso não souberam onde procurar informações sobre o assunto, ou onde procurar ajuda. Essa falta de informação é um dos motivos para que $91,7 \%$ das entrevistadas não denunciassem a agressão.

\subsection{Componentes do Problema}

Com a Definição do Problema estipulada, os Componentes do Problema se tornam, trazer informações e definições sobre o assunto de maneira fácil, mostrar meios para obtenção de ajuda, 
e ainda mapear o ambiente de acordo com a incidência de ocorrências, já que em pesquisa realizada entre os dias 30 de setembro e 8 de outubro de 2017 com 24 participantes, foi uma das funcionalidades listadas como diferencial para as vítimas.

Além desses pontos, a usabilidade e interface devem ser levadas em conta no momento do desenvolvimento, já que o produto deve atender as vítimas de forma fácil para que elas possam recorrer a ele em momentos de choque e tensão. Dessa maneira, a usabilidade deverá ser resolvida estudando o melhor jeito para que o usuário navegue pela aplicação de forma intuitiva e sem estresse durante o uso, tendo uma Interface que deverá trazer facilidade de maneira visual e gráfica.

\subsection{Coleta de Dados}

Foram realizadas 2 pesquisas online com o público alvo (mulheres entre 18 e 30 anos), durante dois períodos distintos e com focos diferentes.

A primeira foi realizada entre 30 de setembro e 8 de outubro de 2017, com 24 participantes, respondendo perguntas específicas para a viabilidade do produto. Nessa pesquisa 95\% dos entrevistados acham importante a criação de um aplicativo que auxilie mulheres na busca por informações sobre abusos.

Segunda pesquisa realizada entre 13 e 18 de junho de 2018 com 48 mulheres, refere-se ao tema de maneira mais específica para definir como vítimas se portam para buscar informações ou ajuda. Essa pesquisa mostrou que $75 \%$ das entrevistadas não soube onde procurar ajuda.

\subsection{Análise dos Dados}

A partir da Coleta de Dados, foi possível identificar a viabilidade e importância do projeto. Além de identificar funcionalidades, prioridades e usabilidade.

O problema inicial que o projeto procura solucionar, é criar mais um meio de divulgar as informações necessárias para vítimas, já que $75 \%$ das entrevistadas nas pesquisas disse que não souberam onde procurar esses dados. Outro problema apresentado, foi que a maioria das vítimas que procuraram ajuda, foram até psicólogas e psiquiatras mulheres, por se sentirem mais confortáveis, assim uma solução encontrada seria a busca por profissionais por região, que mostrasse nome e contato para que as pessoas pudessem ir ao encontro de profissionais especializados no assunto.

Um ponto demonstrado nas pesquisas foi o desconforto e constrangimento às vitimas que procuram por esse tipo de informação, e um aplicativo se torna uma maneira pessoal, e discreta para a obtenção dessas informações.

75\% das 24 entrevistadas em 2017 disseram achar que uma mulher usaria esse aplicativo para buscar ajuda, e 77,5\% disseram que talvez ou teriam esse aplicativo instalado nos celulares para usar em casos de necessidade.

A respeito das funcionalidades as 24 entrevistadas puderam priorizar as que achassem mais importantes, sendo a definição de abusos a mais votada. Estatística que se faz relevante, já que $22,9 \%$ das 48 entrevistadas na segunda pesquisa disseram não saber definir se o que 
passavam se caracterizava como abuso. Uma das funcionalidades ressaltada pelas entrevistadas, foi poder entrar em contato com alguém caso esteja em situação de risco, sendo esse, um diferencial para as vítimas.

Dessa maneira, as pesquisas (Figuras 1 -6) puderam mostrar quais as prioridades devem ser levadas em conta no desenvolvimento do projeto, e o quanto ele é pertinente para o público em questão.

Figura 1 - Análise dos Dados 01

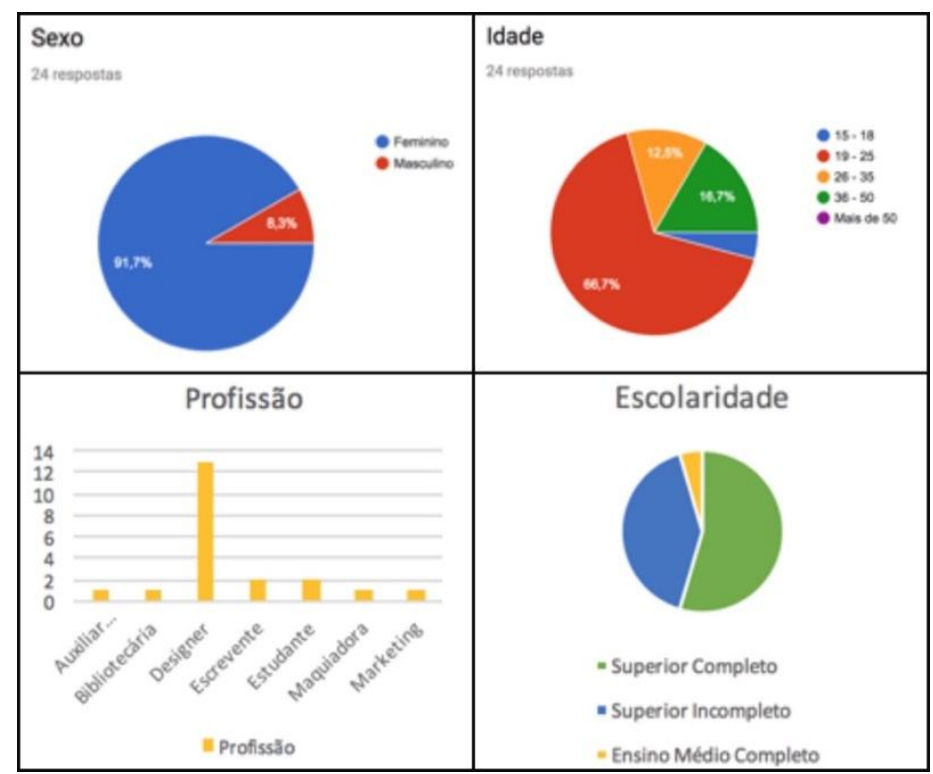

Fonte: da autora (2017)

Figura 2 - Análise dos Dados 02

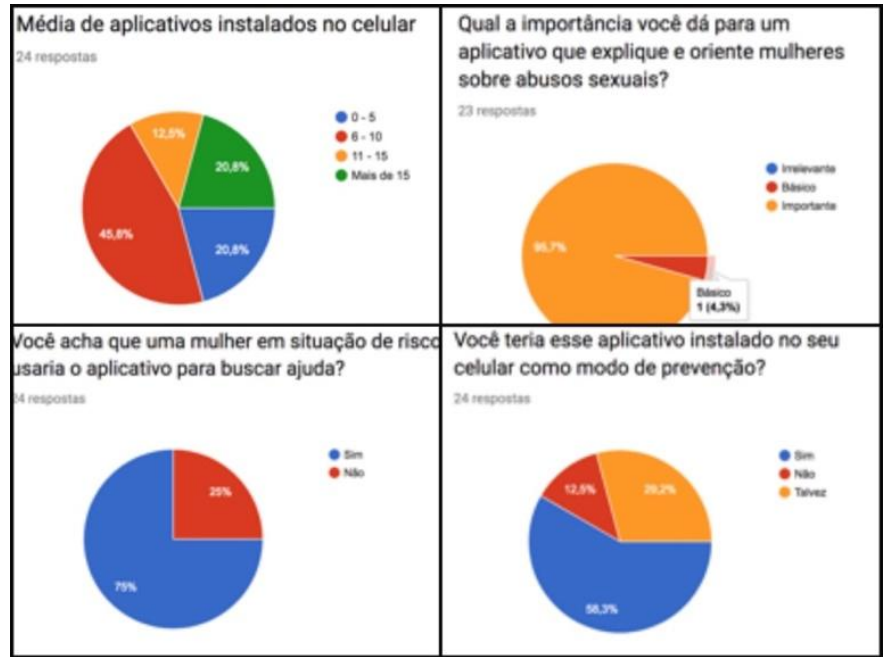

Fonte: da autora (2017) 
Figura 3 - Análise dos Dados 03

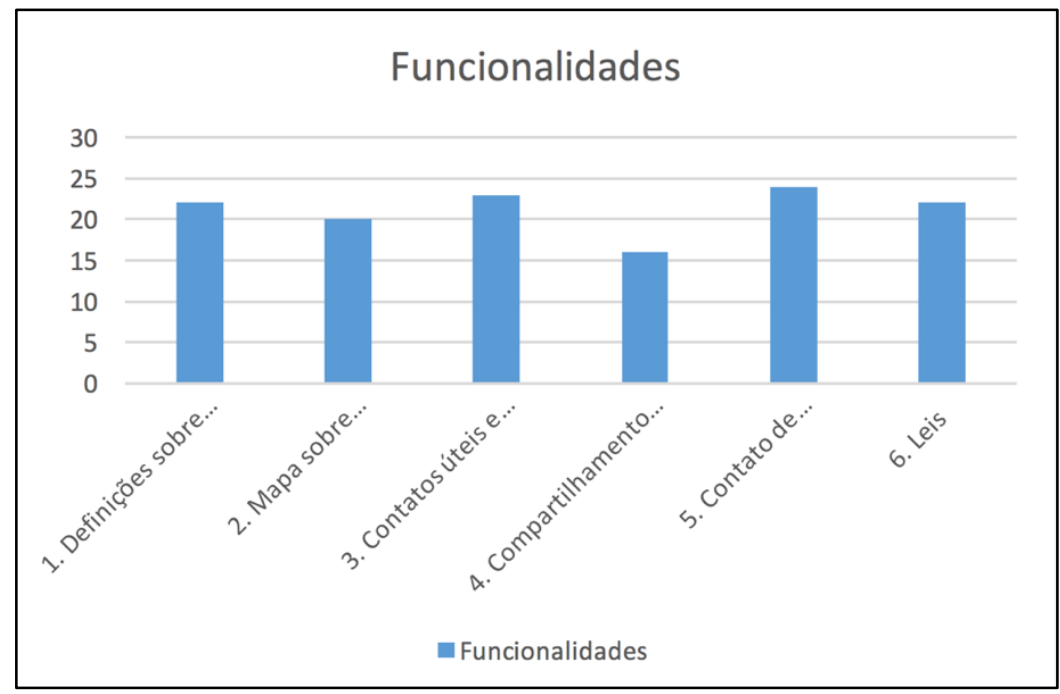

Fonte: da autora (2017)

Figura 4 - Análise dos Dados 04

A partir das funcionalidades citadas acima, enumere das mais importante para a menos

11 respostas

Mapa>compartilhamento>definicoes+leis>Contatos uteis>contato de profissionais MULHERES

Mapa de ocorrencia, contatos uteis,compartilhamento de casos, contato de profissionais e definições de abusos.

Definições sobre abusos; leis; compartilhamento de casos; mapa de ocorrência de abusos; contatos úteis e mais próximos; contatos profissionais

Contatos uteis, leis, contato de profissionais, definições, mapa, compartilhamento de casos

Creio que uma das mais importantes seja o psicólogo, pois poucos têm acesso a isso verdadeiramente. Contatos úteis seriam cruciais em segundo, pois pode ocorrer naquele momento e o 190 somente não está mais resolvendo e sim, virando piada. Depois os outros, por que saindo mais informações como Flyers, né.

Contatos úteis e mais próximos

Contato de profissionais (psicólogos, advogados...)

Definições sobre abusos

Leis

Definições , Contato com prof. , leis e comp.casos

Definição sobre abusos, contatos úteis e mais próximos, contato de profissionais, leis, compartilhamento de casos, mapa sobre ocorrências de abusos.

Mais importante seria a definição de abuso, que podem ocorrer de diversas formas e as vezes a pessoa não identifica que está sofrendo um abuso.

1. Mapa de ocorrências; 2. Definições; 3. Leis; 4 . Compartilhamento de casos; 5 . Contatos úteis; 6 . Contatos profissionais

1. Definições sobre abusos (pra mulher conseguir perceber que tá sendo abusada), 2. Leis (pra ver o q ela pode fazer a respeito), 3. Contatos úteis/contatos de profissionais (com quem ela pode contar)

Fonte: da autora (2017) 
Figura 5 - Análise dos Dados 05

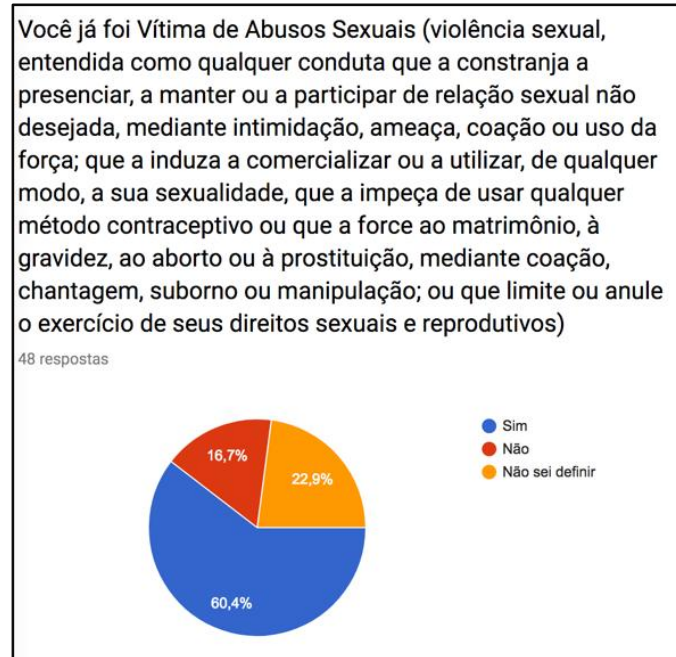

Fonte: da autora (2018)

Figura 6 - Análise dos Dados 06

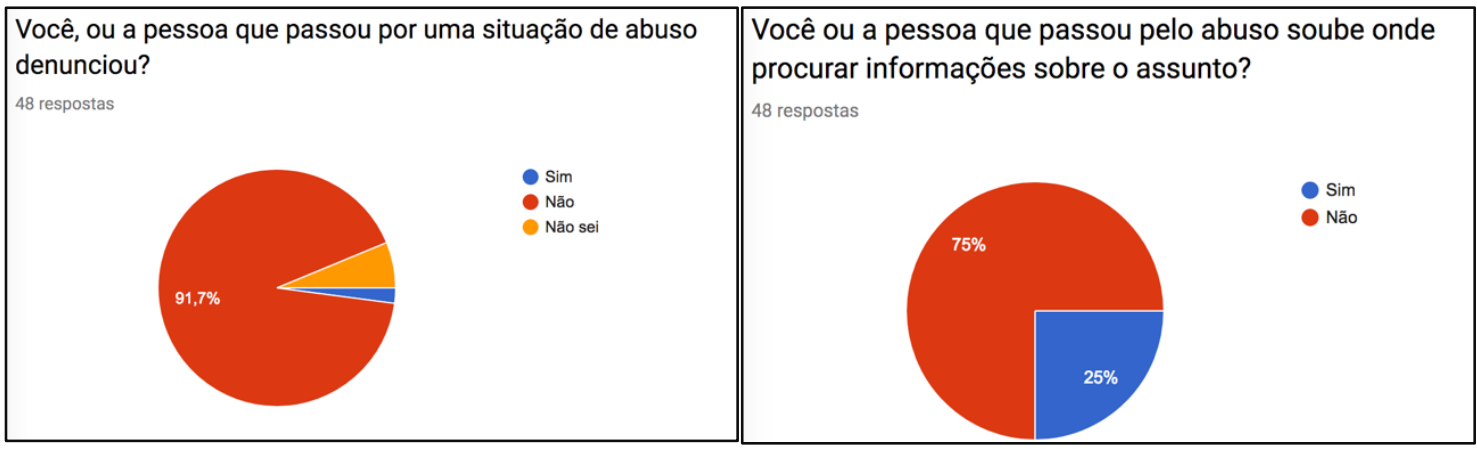

Fonte: da autora (2018)

Ao analisar o resultado da pesquisa, pode-se avaliar a pertinência do aplicativo, pois $95,7 \%$ dos 24 entrevistados julgaram importante a existência do projeto, e $75 \%$ das pessoas disseram achar que uma mulher (o público-alvo) usaria esse aplicativo em um momento de risco.

Já a importância dada para cada funcionalidade obteve uma variação, porém a sequência de prioridades obtida a partir da análise e média das 11 respostas foi a seguinte:

Definição sobre abusos > Contatos úteis > Contatos de Profissionais > Leis > Mapa de ocorrência > Compartilhamento de Casos.

\subsection{Criatividade, Materiais e Tecnologias}

A partir da análise dos dados e das prioridades categorizadas, o desenvolvimento do projeto se inicia, de modo que atenda os usuários da melhor maneira possível.

\subsubsection{Logo}


Pensando em algo que represente a mulher, o projeto foi nomeado como She (Ela), o logo foi feito com a letra S, com formas orgânicas em tons de rosa (\#A70267 e \#F02475) (Figuras 7 e 8).

Figura 7 - Esboços Logo

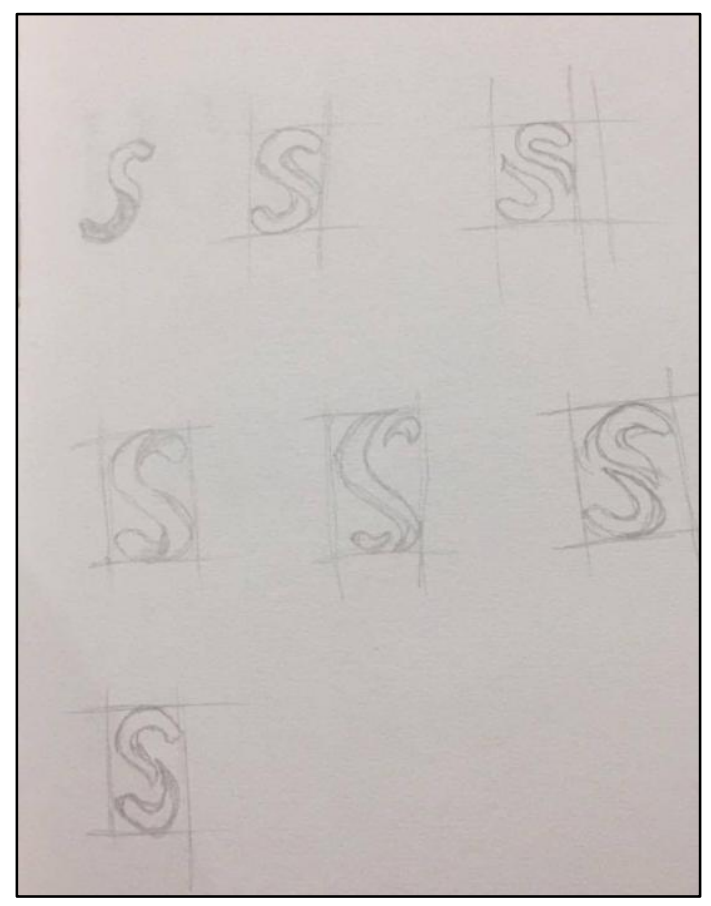

Fonte: da autora (2017)

Figura 8 - Logo Versão Final

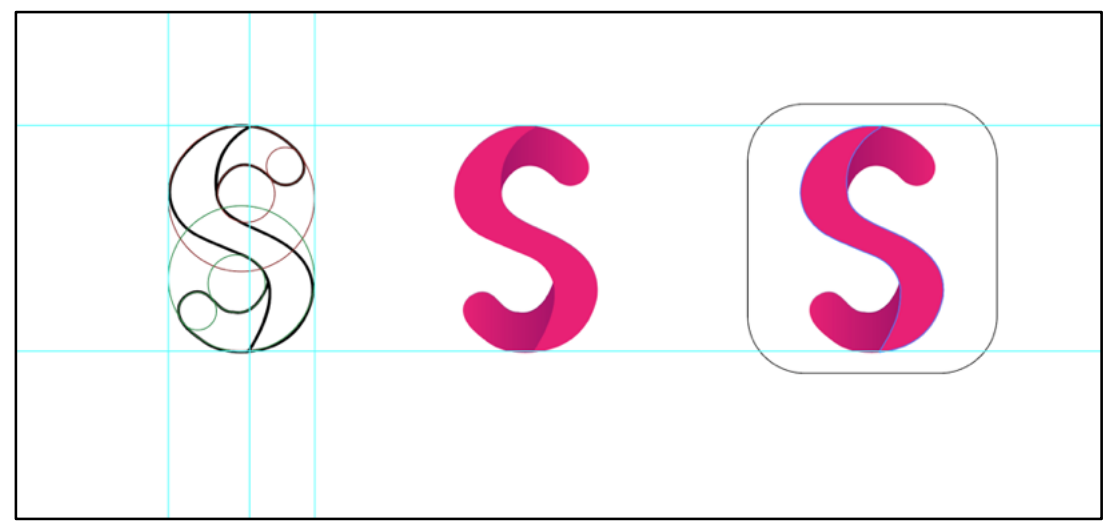

Fonte: da autora (2017)

\subsubsection{Strategy}

No campo da estratégia, que define o objetivo do projeto, a proposta é desenvolver um aplicativo que ajude as mulheres a buscar definições do que são abusos e encontrar ajuda de maneira fácil, intuitiva e discreta. 


\subsubsection{Scope}

De acordo com as pesquisas online com possíveis usuários, algumas funcionalidades foram definidas e suas prioridades dentro do aplicativo, para que ele seja útil e focado ao consumidor. Dessa maneira, o escopo do aplicativo foi definido seguindo as prioridades das funcionalidades listadas: Definição sobre abusos > Contatos úteis > Contatos de Profissionais > Leis > Mapa de ocorrência > Compartilhamento de Casos.

\subsubsection{Structure}

A estrutura de navegação do aplicativo, foi definida de maneira que fosse intuitiva, funcional, e seguisse as prioridades definidas a partir da pesquisa feita com potenciais usuários, seguindo o sitemap mostrado a seguir (Figura 9).

Figura 9 - Sitemap

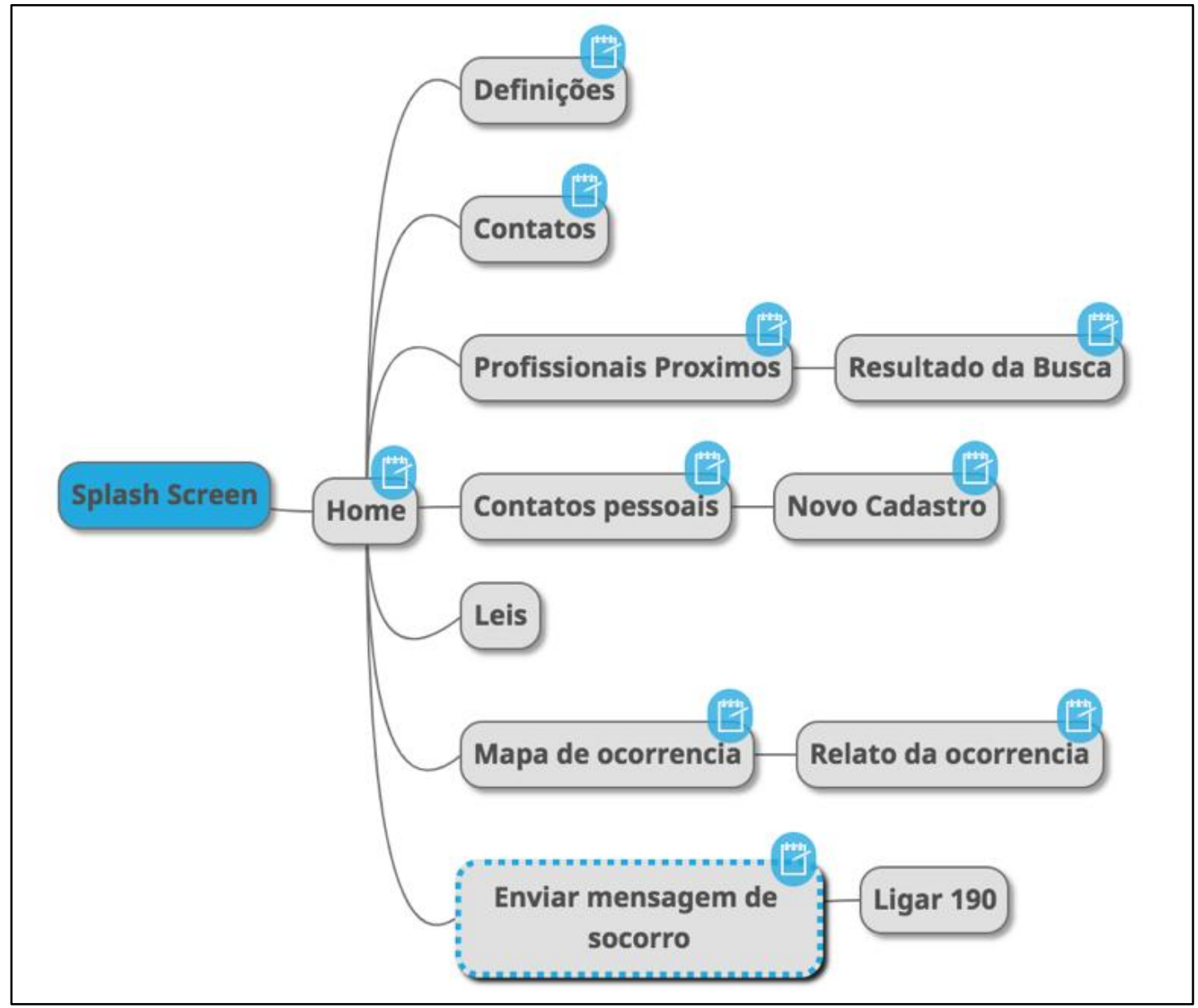

Fonte: da autora (2017)

\subsubsection{Skeleton}

Definido o sitemap com as funcionalidades existentes no aplicativo, foi desenvolvido o wireframe das telas (Figura 10), exemplificando onde ficaria a disposição dos elementos. 
Os elementos foram definidos de maneira que deixasse a navegação simples e intuitiva. A disposição das informações foi feita de maneira objetiva e clara, para que o usuário pudesse se orientar dentro da aplicação de forma rápida. A quantidade de telas e informações foi reduzida ao essencial definido a partir da pesquisa para que o usuário não passe por confusões nem transtornos no momento de usar o produto. Dessa maneira, foi possível priorizar e projetar as informações a serem dispostas da melhor maneira, para que o usuário tenha uma navegação tranquila e sem problemas na utilização.

Figura 10 - Wireframe

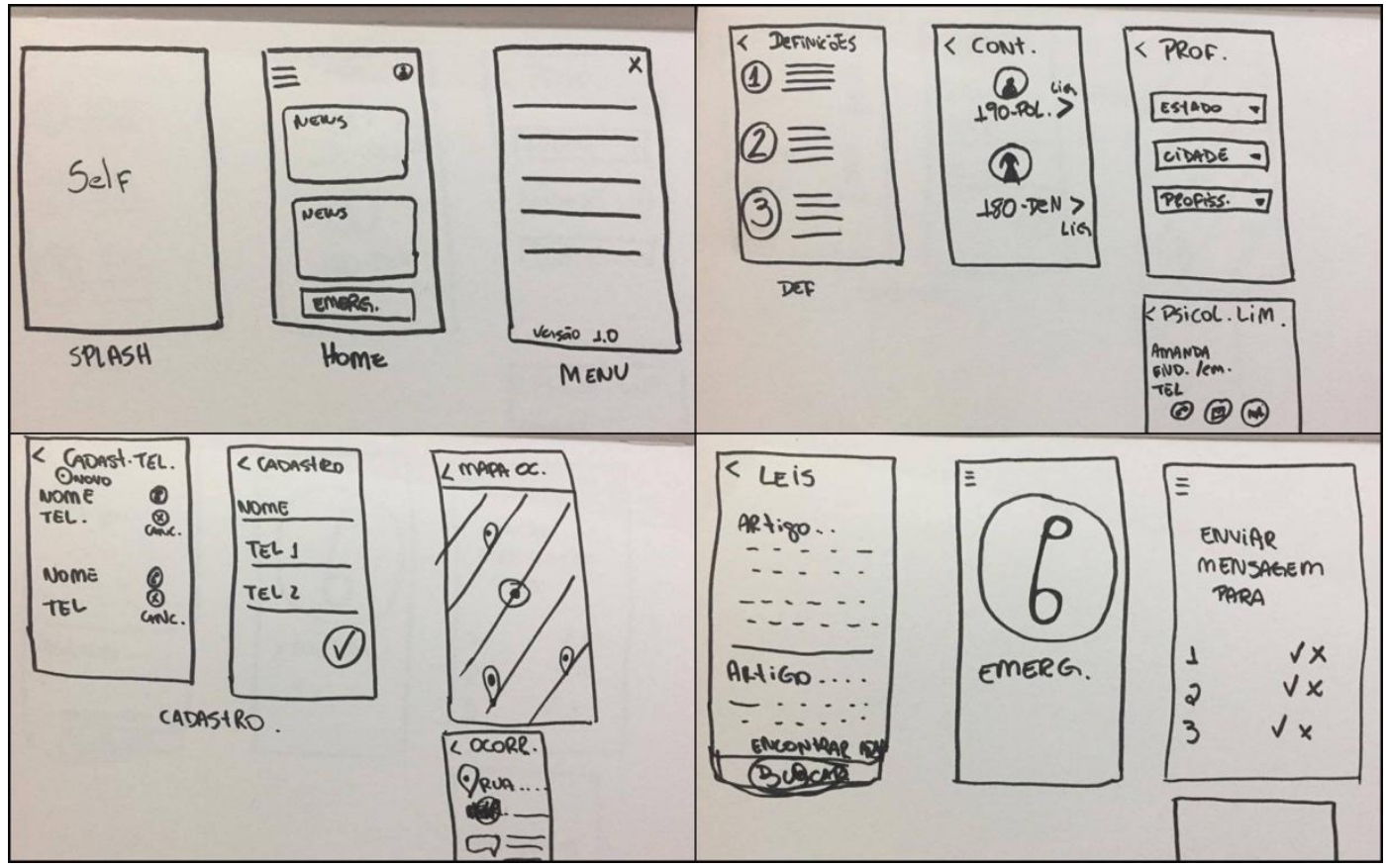

Fonte: da autora (2017)

\subsubsection{Surface}

Após as etapas de estudo, a execução do projeto pode ser realizada. Seguindo os princípios até então estabelecidos, o aplicativo foi finalizado levando sempre em consideração o usuário.

Dessa maneira, foi desenvolvido a interface do aplicativo She. Nele, o sitemap e wireframe foram seguidos para que a produção das telas fossem adequadas a experiência do usuário. $O$ resultado final da pesquisa, foi a produção do aplicativo completo, seguindo padrões visuais. A interação e navegação é feita de maneira simples e intuitiva, auxiliando o usuário na utilização. 


\section{Resultados}

Após as pesquisas com o público alvo, foi possível definir o objetivo principal proposto pelo projeto: criar uma maneira para que mulheres encontrassem informações sobre abusos. Foi a partir das pesquisas que foi determinada as funcionalidades que melhor atendessem às necessidades reais dos usuários. Dessa maneira, o projeto todo foi desenvolvido para ser uma das soluções para o problema encontrado.

Como forma promover a discrição do usuário, o aplicativo foi protegido com senha, promovendo assim um conforto maior para as mulheres que tem o produto instalado em seus celulares. Para auxiliar o consumidor, a primeira funcionalidade escolhida foi a de emergência, onde a vítima pode mandar mensagem padrão para um contato cadastrado no aplicativo de que está em risco.

O maior problema detectado nas pesquisas foi a falta de canais para a busca de definições, já que parte das mulheres não sabiam definir se o que passaram se caracterizava como abuso, portanto, a segunda funcionalidade é a de informações, seguidas por contatos úteis, como da polícia e de denúncias, que podem ser feitos direto do aplicativo.

A próxima funcionalidade são os meus contatos, onde o usuário pode cadastrar as pessoas que serão contatadas nos casos em que a emergência foi acionada. Em seguida está a busca por profissionais por localização e especialidade, trazendo assim um banco de dados de profissionais que podem ser encontrados para buscar ajuda.

Encontrado como problema a falta de informação, a próxima funcionalidade é a definição por leis, que assim que identificado um abuso, o usuário já pode procurar um profissional para ajuda-lo a partir daquela tela. Por último, foi colocado o mapa de ocorrências, que faz o mapeamento de ocorrências de abuso por localização. $O$ usuário pode entrar e cadastrar o ocorrido, fazendo assim um alerta para as pessoas sobre a região.

Todo o projeto (figuras 11 - 13) foi estruturado a partir da viabilidade do projeto, projetado para que as informações ficassem objetivas, para que a usabilidade ficasse intuitiva e a interface clara para que o usuário concluísse seu objetivo dentro do projeto.

Figura 11 - Telas 01

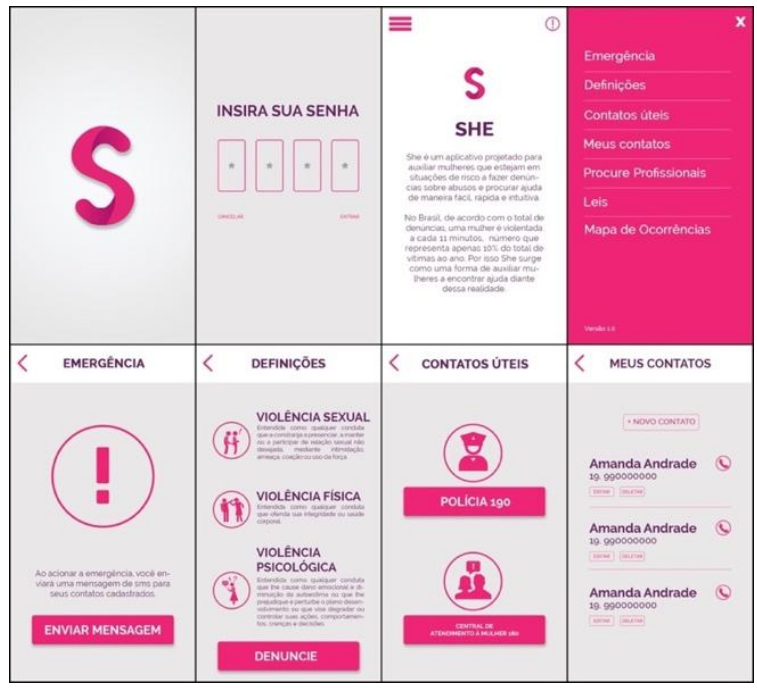

Fonte: da autora (2017) 
Figura 12 - Telas 02

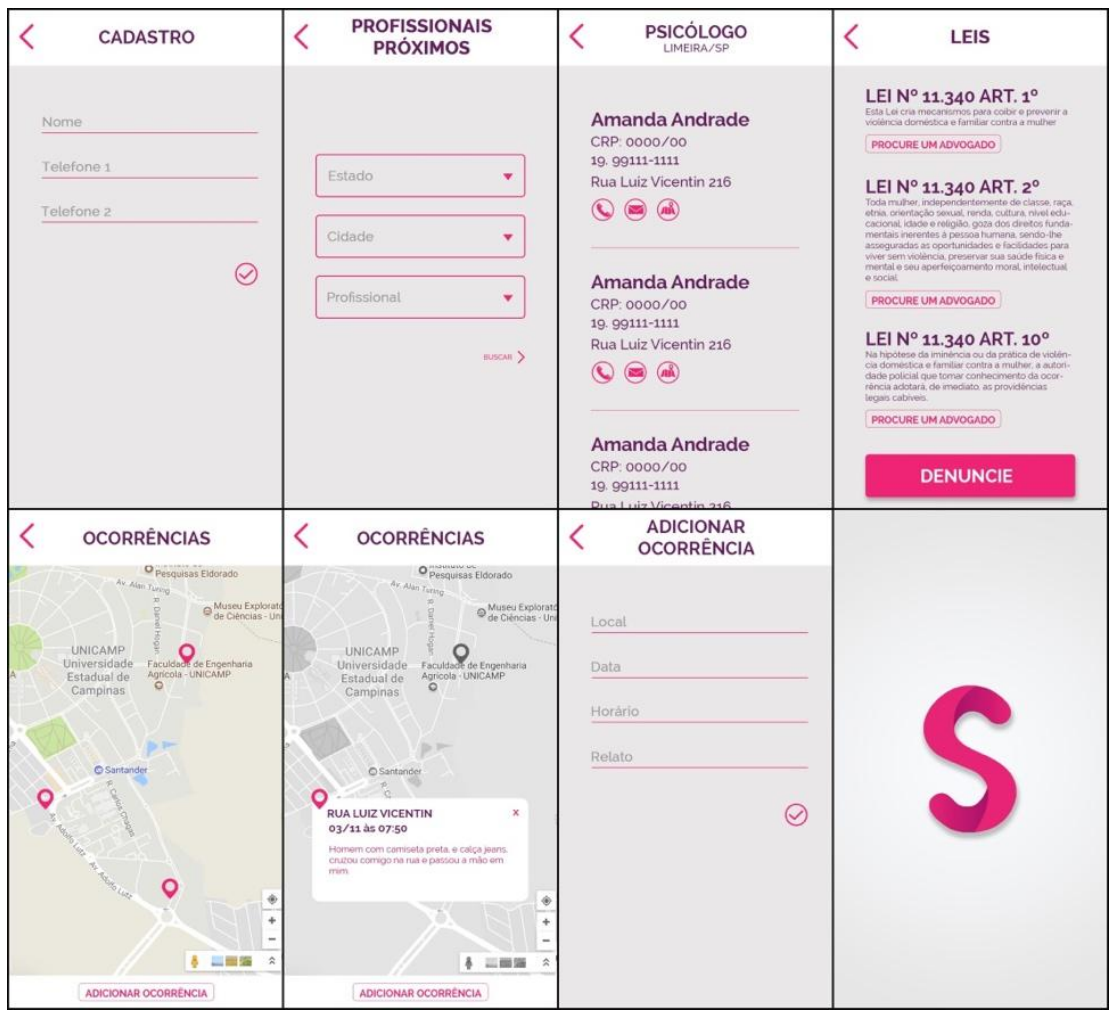

Fonte: da autora (2017)

Figura 13 - Mockup 01

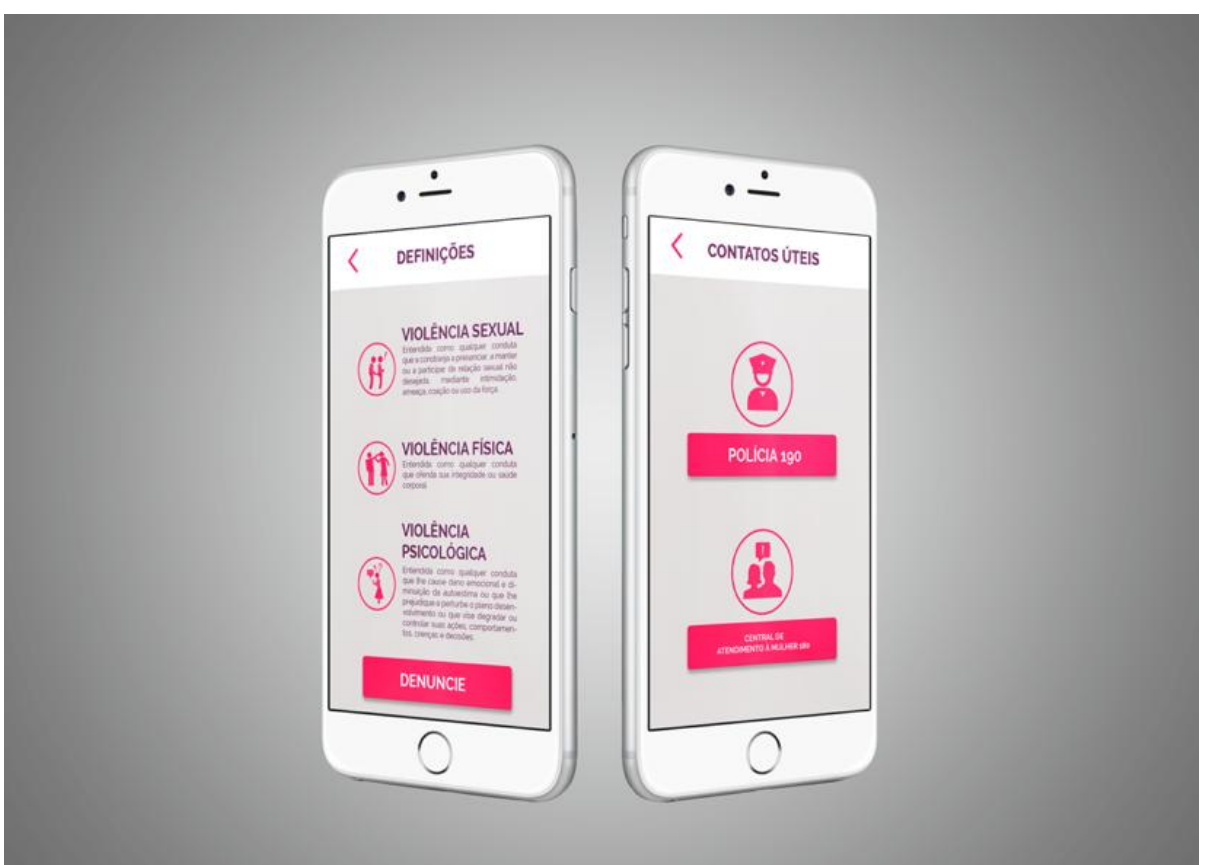

Fonte: da autora (2017) 


\section{Considerações Finais}

Diante da realidade em que as mulheres vivem no Brasil nos dias de hoje na qual uma mulher é estuprada a cada 11 minutos (FORUM BRASILEIRO DE SEGURANÇA PÚBLICA, 2016), torna-se indispensável a criação de meios que facilitem o encontro de informações e busca de ajuda das mais diversas maneiras. Assim, chegou-se a conclusão de que uma opção viável seria a criação de um aplicativo que englobe as principais funcionalidades definidas por possíveis usuários, para que auxilie as vítimas em situações de risco.

A pesquisa feita provou a viabilidade do projeto, e a solução proposta, da criação de um aplicativo móvel, é pertinente, considerando que o Brasil é o 60 no mercado mundial de smartphones (DINO, 2016), sendo que o número de usuárias mulheres de telefonia móvel, público alvo proposto, ultrapassou o número de usuários homens (IBGE - INSTITUDO BRASILEIRO DE GEOGRAFIA E ESTATÍSTICA, 2011).

Além disso, depois da pesquisa com o público alvo, foi notado que o número de mulheres que já passaram por algum tipo de abuso sexual, ou conhece alguém que já passou pesa situação supera $80 \%$ das entrevistadas. Sendo que $75 \%$ das vítimas não souberam onde buscar informações.

Assim, após concluídas as pesquisas teóricas e quantitativas com o público alvo, pode-se basear o desenvolvimento do projeto do aplicativo de acordo com as necessidades do usuário, definindo assim as funcionalidades mais importantes, a maneira de como deixar a interface mais intuitiva e a navegação fácil e objetiva.

Dessa maneira, She foi projetado para cumprir seu papel dentro do cenário crítico em que as vítimas se encontram, ajudando mulheres que precisam obter informações e buscar ajuda quando estão em situação de risco. O aplicativo foi desenvolvido pensando em seu público alvo, e em como trazer mais comodidade em emergências, permitindo ao usuário atingir seu objetivo dentro da aplicação, sem traumas e sem complicações durante a navegação. 


\section{Referências}

BRASIL. Presidência da República. Lei 11340. Planalto, 2006. Disponivel em: <http://www.planalto.gov.br/ccivil_03/_ato2004-2006/2006/lei/l11340.htm>.

CAPITAL, Carta. No Brasil, um estupro a cada 11 minutos. 11 mar. 2016. Disponivel em: <https://www.cartacapital.com.br/sociedade/no-brasil-um-estupro-a-cada-11-minutos>.

DINO. Estatísticas de uso de celular no Brasil. Exame.com, 22 abr. 2016. Disponivel em: $<$ http://exame.abril.com.br/negocios/dino/estatisticas-de-uso-de-celular-no-brasildino89091436131/>.

ESTADÃO. Veja casos de violência sexual contra mulher que chocaram o Brasil e o mundo. Estadão, 31 maio 2016. Disponivel em: <http://fotos.estadao.com.br/galerias/brasil,veja-casos-deviolencia-sexual-contra-mulher-que-chocaram-o-brasil-e-o-mundo,25484>.

FORUM BRASILEIRO DE SEGURANÇA PÚBLICA. Anuário Brasileiro de Segurança Pública. 10. ed. [S.I.]: [s.n.], 2016.

GARRET, J. J. The Elements of User Experience: User-Centered Design for the Web and Beyond. 2nd Edition. ed. Berkeley: New Riders, v. I, 2011.

IBGE - INSTITUTO BRASILEIRO DE GEOgRAfIA E ESTATístiCA. PNAD - Pesquisa Nacional por Amostra de Domicílios. [S.I.]. 2011.

IBGE - INSTITUTO BRASILEIRO DE GEOGRAFIA E ESTATÍSTICA. Pesquisa Nacional por Amostra de

Domicílios. [S.I.]. 2014.

IPEA - INSTITUTO DE PESQUISA ECONÔMICA APLICADA. Estupro no Brasil: uma radiografia segundo os dados da Saúde (versão preliminar). [S.I.]: [s.n.], 2014.

MUNARI, Bruno. Das Coisas Nascem Coisas. Editora Martins. 3. Edição, 2015.

REISS, E. Usable Usability - Simple Steps for Making Stuff Better. Indianapolis: John Wiley \& Sons, Inc., v. 1, 2012.

SPM - SECRETARIA ESPECIAL DE POLÍTICAS PARA AS MULHERES. Carta de Serviços. SPM Secretaria Especial de Políticas para as Mulheres, 26 mar. 2015. Disponivel em: <http://www.spm.gov.br/assuntos/carta-de-servicos>. 